\title{
Effect of Cover Crop on Carbon Distribution in Size and Density Separated Soil Aggregates
}

\author{
Michael V. Schaefer ${ }^{1,2}{ }^{(}$, Nathaniel A. Bogie ${ }^{3,4}{ }^{(0}$, Daniel Rath ${ }^{5}$, Alison R. Marklein ${ }^{1,6}$, \\ Abdi Garniwan ${ }^{1}$, Thomas Haensel ${ }^{1}$, Ying Lin ${ }^{7}$, Claudia C. Avila ${ }^{1}{ }^{\mathbb{D}}$, Peter S. Nico ${ }^{6}$, \\ Kate M. Scow ${ }^{5,8}$, Eoin L. Brodie ${ }^{6,9}$, William J. Riley ${ }^{6}\left(\mathbb{D}\right.$, Marilyn L. Fogel ${ }^{7,10}$, \\ Asmeret Asefaw Berhe ${ }^{3}(\mathbb{D})$, Teamrat A. Ghezzehei ${ }^{3}$, Sanjai Parikh ${ }^{5} \mathbb{D}$, Marco Keiluweit 11 and \\ Samantha C. Ying ${ }^{1,12, *}$
}

1 Department of Environmental Sciences, University of California, Riverside, CA 92521; USA; mschaef@ucr.edu (M.V.S.); alison.marklein@ucr.edu (A.R.M.); agarn005@ucr.edu (A.G.); thaen001@ucr.edu (T.H.); cmari009@ucr.edu (C.C.A.)

2 Pacific Basin Research Center, Soka University of America, Laguna Hills, CA 92656, USA

3 Environmental System, University of California, Merced, CA 95343, USA; nathaniel.bogie@sjsu.edu (N.A.B.); aaberhe@ucmerced.edu (A.A.B.); taghezzehei@ucmerced.edu (T.A.G.)

4 Geology Department, San Jose State University, San Jose, CA 95192, USA

5 Department of Land, Air, and Water Resource, University of California, Davis, CA 95616, USA; darath@ucdavis.edu (D.R.); kmscow@ucdavis.edu (K.M.S.); sjparikh@ucdavis.edu (S.P.)

6 Earth and Environmental Sciences, Lawrence Berkeley National Laboratory, Berkeley, CA 94720, USA; PSNico@lbl.gov (P.S.N.); eoin_brodie@berkeley.edu (E.L.B.); wjriley@lbl.gov (W.J.R.)

7 Environmental Dynamics and GeoEcology Institute, University of California, Riverside, CA 92521, USA; yinglin@ucr.edu (Y.L.); marilyn.fogel@ucr.edu (M.L.F.)

8 Agricultural Sustainability Institute, University of California, Davis, CA 95616, USA

9 Department of Environmental Science, Policy and Management, University of California, Berkeley, CA 94720, USA

10 Department of Earth and Planetary Sciences, University of California, Riverside, CA 92521, USA

11 School of Earth \& Sustainability and Stockbridge School of Agriculture, University of Massachusetts, Amherst, MA 01003, USA; keiluweit@umass.edu

12 California Agriculture and Food Enterprise Institute, University of California, Riverside, CA 92521, USA

* Correspondence: samying@ucr.edu; Tel.: +1-951-827-4505

Received: 19 October 2019; Accepted: 8 January 2020; Published: 15 January 2020

\begin{abstract}
Increasing soil organic carbon (SOC) stocks in agricultural soils can contribute to stabilizing or even lowering atmospheric greenhouse gas (GHG) concentrations. Cover crop rotation has been shown to increase SOC and provide productivity benefits for agriculture. Here we used a split field design to evaluate the short-term effect of cover crop on SOC distribution and chemistry using a combination of bulk, isotopic, and spectroscopic analyses of size-and density-separated soil aggregates. Macroaggregates $(>250 \mu \mathrm{m})$ incorporated additional plant material with cover crop as evidenced by more negative $\delta^{13} \mathrm{C}$ values $(-25.4 \%$ o with cover crop compared to $-25.1 \%$ o without cover crop) and increased phenolic (plant-like) resonance in carbon NEXAFS spectra. Iron EXAFS data showed that the Fe pool was composed of $17-21 \%$ Fe oxide with the remainder a mix of primary and secondary minerals. Comparison of oxalate and dithionite extractions suggests that cover crop may also increase Fe oxide crystallinity, especially in the dense $\left(>2.4 \mathrm{~g} \mathrm{~cm}^{-3}\right)$ soil fraction. Cover crop $\delta^{13} \mathrm{C}$ values were more negative across density fractions of bulk soil, indicating the presence of less processed organic carbon. Although no significant difference was observed in bulk SOC on a mass per mass basis between cover and no cover crop fields after one season, isotopic and spectroscopic data reveal enhanced carbon movement between aggregates in cover crop soil.
\end{abstract}


Keywords: cover crop; soil organic carbon; aggregation; NEXAFS spectroscopy

\section{Introduction}

Efforts to sequester carbon (C) in soil, such as the four per mille soil carbon campaign [1], utilize agricultural soil management practices to increase soil organic $\mathrm{C}$ (SOC) stocks and offset some portion of greenhouse gas (GHG) emissions. Central to this strategy is planting cover crop (CC), which may increase SOC stocks and is estimated to potentially compensate for up to $8 \%$ of direct agricultural GHG emissions [2]. Recent calculations show that agricultural land management, of which CC plays a key role, has the potential to lower Earth's surface temperatures by $0.1-0.26{ }^{\circ} \mathrm{C}$ under various implementations and climate projection scenarios [3].

A critical component of overall soil health, and especially increasing SOC storage, is soil aggregation. Aggregation affects the capacity of soils to retain carbon, nutrients, and water, and CC rotation is one strategy to promote soil aggregation and structure while providing C inputs to soil [4]. For example, growth of $\mathrm{CC}$ has been shown to increase wet soil aggregate mean weight diameter (MWD) by 55\% (0-10 cm) after four years in no-till corn fields [5]. Previous studies of aggregation and CC have largely focused on changes in the distribution of size-defined water stable aggregates following a change in management. For example, winter wheat and dandelion led to similar increases in water stable soil aggregates compared to fallow soil after a single season of CC [6], and two seasons of grass CC led to decreased slaking of macroaggregates [7]. However, little is known about the mechanisms and time frames of aggregate formation, destruction, and reformation or how CC or other management practices impact this cycle.

Carbon addition to soil with CC is achieved both through increased root growth and incorporation of above-ground biomass into soil during tillage. A study using ${ }^{13} \mathrm{C}$-labeled hairy vetch showed that root- $C$ contributed $>10$ times more $C$ to soil than residue- $C$ at the end of the growing season [8]. A subsequent study highlighted the importance of microbial communities and their microenvironments (e.g., soil aggregate size) on rhizodeposition of C [9].

Carbon and iron $(\mathrm{Fe})$ are essential soil nutrients that play key roles in formation and stability of soil aggregates $[10,11]$. For example, organic matter associated with poorly crystalline Fe minerals has been shown to be more resistant to microbial degradation [12], and poorly crystalline Fe oxides are more effective than crystalline oxides at stabilizing soil aggregates [13]. The concentrations and chemical composition of $C$ and Fe species in different soil aggregate fractions and their role in driving aggregate formation and stability remain poorly understood, especially in agricultural soils where CC, especially CC roots, may provide a "pipeline" for C incorporation into soil.

If cover crops support $C$ incorporation into aggregates, it may serve as an efficient $C$ sink because decomposition rates of $C$ are reduced within aggregates [14]. However, root addition has also been shown to destroy protective mineral-organic associations [15]. Therefore, the objective of this study was to analyze the chemical distribution and composition of $C$ and Fe in soil aggregates from a short-term (1 year) field experiment that differed only by the presence of CC. Samples in this study were taken prior to $\mathrm{CC}$ incorporation to isolate the effect of $\mathrm{CC}$ roots on SOC and aggregate changes.

\section{Materials and Methods}

\subsection{Field Setting and Sample Collection}

Soil samples were collected at the Russell Ranch Sustainable Agricultural Facility from fields developed on Rincon silty clay loam (fine, montmorillonitic, thermic Mollic Haploxeralf). Fields were irrigated using subsurface drip application and planted with processing tomatoes in 2015, left fallow, then planted with processing tomatoes again in 2016. Following harvest in 2016, the field was divided so that half was left fallow and the other half planted with cover crop consisting of a mix of vetch 
(Vicia villosa), bell bean (Vicia faba), and Austrian pea (Pisum sativum). Planting cover crop resulted in an additional mechanical disturbance compared to no cover crop. Soil samples were collected from the top $10 \mathrm{~cm}$ of both fallow and cover crop fields in March 2017 prior to incorporation of cover crop. Four locations in each field were selected for sampling, and at each location four soil cores were composited to create a single field replicate sample at each location. The two treatments are referred to as NCC (no cover crop) and CC (cover crop). Soil pH measured at the time of soil collection was $7.04 \pm 0.02$ for CC and $7.43 \pm 0.02$ for NCC.

\subsection{Aggregate Size Separation}

Samples were separated into size classes of water stable aggregates following the method of Six [16]. Briefly, field-moist samples were passed through an $8 \mathrm{~mm}$ sieve to remove gravel and large plant material then air dried before aggregate size separation. Subsamples of field fresh samples were weighed and oven dried to obtain their water contents. Aggregates were then submerged (slaked) and moved in and out of water at a rate of 25 cycles $\mathrm{min}^{-1}$ for two minutes in a $2 \mathrm{~mm}$ sieve. The process was then repeated using $250 \mu \mathrm{m}$ and $53 \mu \mathrm{m}$ sieves on the soil that passed through the $2 \mathrm{~mm}$ sieve. Fractions retained on sieves were dried in an oven at $50^{\circ} \mathrm{C}$, weighed to determine mass proportions of each size fraction, and stored in glass vials for further analysis. Mass recovery as calculated by comparing the sum of fraction masses to the initial soil mass was typically $98-100 \%$.

\subsection{Aggregate Density Separation}

Bulk soil samples and micro- $(<53$ and 53-250 $\mu \mathrm{m})$ and macro-aggregates $(250-2000 \mu \mathrm{m})$ from the $0-10 \mathrm{~cm}$ sampling interval were separated into density fractions of $<1.65,1.65-2.4$, and $>2.4 \mathrm{~g}$ $\mathrm{cm}^{-3}$ using sodium polytungstate (SPT) solutions [17-19]. Briefly, $3 \mathrm{~g}$ of sample was suspended in $12 \mathrm{~mL}$ of $1.65 \mathrm{~g} \mathrm{~cm}^{-3}$ SPT solution and gently dispersed on a shaker table operating at $60 \mathrm{rpm}$ for $2 \mathrm{~h}$. The suspension was then centrifuged at $2000 \times g$ for $30 \mathrm{~min}$. The material that did not settle (i.e., material with a density $<1.65 \mathrm{~g} \mathrm{~cm}^{-3}$ ) and the solution were removed with a transfer pipette and filtered through a pre-weighed mixed cellulose ester (MCE) filter (pore size 0.45 micron) using a vacuum filtration apparatus. Each sample was washed with $>40 \mathrm{~mL}$ of DI water to remove excess SPT. The remaining material (density $>1.65 \mathrm{~g} \mathrm{~cm}^{-3}$ ) was resuspended in $12 \mathrm{~mL}$ of SPT solution with density of $2.4 \mathrm{~g} \mathrm{~cm}^{-3}$, shaken at $60 \mathrm{rpm}$ for $2 \mathrm{~h}$, and centrifuged at $2000 \times \mathrm{g}$. The non-settling fraction was removed, filtered, and washed. The settled fraction $\left(2.4 \mathrm{~g} \mathrm{~cm}^{-3}\right)$ was washed three times with DI water to remove excess SPT. Fractions were then freeze dried and weighed to determine mass distribution in each fraction. The particles separated into these fractions are termed "light", "intermediate", and "heavy" fractions and represent free particulate organic matter (POM), OM co-precipitated with metal (hydr) oxides, and OM coated on mineral surfaces, respectively [17-21].

\subsection{Elemental and Isotopic Analysis}

Bulk elemental analysis for samples with sufficient mass available was determined using energy dispersive X-ray fluorescence (ED-XRF) spectroscopy (Spectro XEPOS). A finely ground sample $(\sim 2 \mathrm{~g})$ was placed in a plastic cup fitted with a thin layer of polypropylene Prolene film (Chemplex). $\mathrm{X}$-rays were generated with a 50 -watt $\mathrm{X}$-ray tube and fluorescent $\mathrm{X}$-rays were detected on five energy targets to cover the elemental range from sodium to uranium. Measurements were performed in a $\mathrm{He}$ atmosphere to minimize X-ray attenuation between the sample and target. Bulk elemental abundance was calculated based on the intensity of the characteristic fluorescent X-rays of each element.

Carbon and nitrogen content and $\delta^{13} \mathrm{C}$ and $\delta^{13} \mathrm{~N}$ values of samples were determined by combusting the finely ground sample using a Costech ECS 4010 CHNSO Analyzer coupled to a Thermo Scientific Delta V Advantage Isotope Ratio Mass Spectrometer at the UC Riverside EDGE Institute stable isotope laboratory. Depending on the carbon content of the soil, 10 to $25 \mathrm{mg}$ of sample was weighed into $5 \times 9 \mathrm{~mm}$ tin capsules and measured relative to acetanilide, glycine, peach leaves (NIST1547) and an internal soil laboratory standard as reference materials. The stable isotope ratios are presented using 
the $\delta$ notation (per mill, $\%$ o) as $\delta^{13} \mathrm{C}$ and $\delta^{15} \mathrm{~N}$ calculated as: $\delta=$ [(R_sample $\left.\left.-\mathrm{R} \_s t a n d a r d\right) R \_s t a n d a r d\right]$ $\times 1000 \%$; where $\mathrm{R}$ is ratio of ${ }^{13} \mathrm{C}^{12} \mathrm{C}$ for $\delta^{13} \mathrm{C}$, and ${ }^{15} \mathrm{~N}^{14} \mathrm{~N}$ for $\delta^{15} \mathrm{~N}$. The international measurement standards used in the $\delta$ notation are atmospheric $\mathrm{N}_{2}$ for $\delta^{15} \mathrm{~N}$ and Vienna Pee Dee Belemnite (VPDB) for $\delta^{13} \mathrm{C}$. Precisions for $\delta^{15} \mathrm{~N}$ and $\delta^{13} \mathrm{C}$ are 0.2 and $0.1 \%$, respectively.

\subsection{X-ray Absorption Spectroscopy}

Bulk C 1s near edge X-ray absorption fine structure (NEXAFS) spectra were collected at the high resolution spherical grating monochromator (SGM) beamline (11ID-1) at the Canadian Light Source (CLS) [22]. Subsamples of dried material $(<50 \mathrm{mg})$ were suspended in $\sim 1 \mathrm{~mL}$ of deionized water in a microcentrifuge tube and briefly mixed on a vortex mixer. Following homogenization, 10-30 $\mu \mathrm{L}$ of the suspension was dropped onto gold-coated Si wafers and allowed to dry. Samples were affixed to an aluminum holder using carbon tape and inserted into the beamline under vacuum ( $\sim 10^{-7}$ torr). Samples were scanned from 270 to $320 \mathrm{eV}$ in continuous (fast) scan mode. Each scan lasted $60 \mathrm{~s}$ and typically 30 scans were collected per sample. The beam was moved to a fresh area of the sample between each scan to minimize data artifacts associated with beam damage to the sample [23]. Fast scan data were averaged and binned into $1 \mathrm{eV}$ steps using macros (SGMPy) developed at SGM implemented in NeXpy software (http://nexpy.github.io/nexpy/). Effects of X-ray scattering were removed by normalizing to the scattering spectrum of a blank gold-coated Si wafer, and energy was calibrated to the carboxylic peak of citric acid set to $288.5 \mathrm{eV}$. Spectra were normalized to an edge jump of unity by fitting functions to pre-and post-edge regions of the spectra in Athena Software [24]. Spectral deconvolution was performed on normalized spectra by fitting an arctangent function with fixed height of 1 to the ionization threshold at $290 \mathrm{eV}$, and fitting Gaussian peaks to spectral features with known energies. Gaussian energy positions and full width at half maximum (FWHM) values were fixed, and only peak height was allowed to float. Fits were optimized by minimizing the residual least-squares function within these constraints.

Bulk Fe K-edge extended x-ray absorption fine structure (EXAFS) spectroscopy was performed at the Stanford Synchrotron Radiation Lightsource (SSRL) Beamline 4-1. Energy was calibrated to the first inflection point of Fe foil and set to $7112 \mathrm{eV}$. A small amount of finely ground sample was packed into an aluminum sample plate between two pieces of 0.5 mil Kapton tape and placed at 45 degrees relative to the beam path under liquid nitrogen cryostat conditions ( $\sim 77 \mathrm{~K}$ and $10^{-7}$ torr). Spectra were collected in $5 \mathrm{eV}$ steps below the edge $(6802-7092 \mathrm{eV})$, in $0.25 \mathrm{eV}$ steps at the edge (7092-7142 eV), and in steps equivalent to $0.05 \AA^{-1}$ above the edge to $\mathrm{k}=13 \AA^{-1}$. Fluorescent $\mathrm{X}$-rays were detected with a passivated implanted planar silicon (PIPS) detector. Soller slits and a 3 absorption length Mn filter were used to reduce scattering and background signal.

Pre-and post-edge features were fit with linear and $3^{\text {rd }}$ order functions, respectively, and background was fit using the Autoback function in Athena software. Data were transformed into k-space, weighted by $\mathrm{k}^{3}$, and fit in the range 3-12 $\AA^{-1}$. Experimental data were fit using a linear combination of standard spectra to minimize the least squares error. An initial set of 24 standards was used including $\mathrm{Fe}$ in oxides, hydroxides, oxyhydroxides, and sulfides; primary and secondary silicates, siderite $\left(\mathrm{FeCO}_{3}\right)$ and vivianite $\left(\mathrm{FePO}_{4}\right)$, and ferrous oxalate $\left(\mathrm{FeC}_{2} \mathrm{O}_{4}\right)$. Non-relevant standards were eliminated from analysis step-wise and fits for each sample converged on a set of five common standards: goethite ( $\alpha$-FeOOH, synthesized), hornblende (amphibole, Stanford Mineral Collection), nontronite (Fe-rich smectite, NAu-2, Source Clay Repository), phlogopite (magnesium mica, Stanford Mineral Collection), and vermiculite (2:1 clay mineral, typical weathering product of phlogopite, Stanford Mineral Collection).

\subsection{Chemical Extractions}

Citrate-bicarbonate-dithionite (CBD) and ammonium oxalate extractions [25] were performed on bulk soil as well as size and density fractions. $\mathrm{CBD}$ extractions were performed by mixing $6.75 \mathrm{~mL}$ of $1 \mathrm{M} \mathrm{NaHCO}_{3}$ and $0.75 \mathrm{~mL}$ of $0.3 \mathrm{M} \mathrm{NaC}_{6} \mathrm{H}_{7} \mathrm{O}_{7}$ with $0.15 \mathrm{~g}$ of soil in a $15 \mathrm{~mL}$ Falcon centrifuge 
tube. Samples were mixed on a shaker table at $90 \mathrm{rpm}$ and then equilibrated in a water bath at $80^{\circ} \mathrm{C}$. Samples were briefly removed from the bath to add $0.15 \mathrm{~g}$ of $\mathrm{Na}_{2} \mathrm{~S}_{2} \mathrm{O}_{4}$ then placed back in the bath for $15 \mathrm{~min}$ with periodic mixing. This step was repeated with an additional $0.15 \mathrm{~g} \mathrm{of} \mathrm{Na}_{2} \mathrm{~S}_{2} \mathrm{O}_{4}$ and mixed for $10 \mathrm{~min}$. Samples were then cooled and centrifuged, and supernatant was filtered through $0.22-\mu \mathrm{m}$ filter prior to analysis on ICP-OES.

Oxalate extractions were performed using $\sim 0.25 \mathrm{~g}$ sample mixed with $10 \mathrm{~mL}$ of $0.2 \mathrm{M}$ oxalate solution adjusted to $\mathrm{pH} 3$ using $0.2 \mathrm{M}$ oxalic acid. Samples were briefly mixed on a vortex agitator then placed on a rotary shaker $(90 \mathrm{rpm})$ for $4 \mathrm{~h}$ in the dark. Samples were then centrifuged and supernatant filtered $(0.22-\mu \mathrm{m})$ prior to analysis on ICP-OES.

Extractable Fe concentrations were determined using ICP-OES. Measured aqueous concentrations were converted to soil extractable mass concentrations and reported as $\mathrm{mg}$ Fe per $\mathrm{kg}$ dry soil. Analyses of bulk soil and size fractions were performed in triplicate. Density fraction samples were extracted in triplicate when sufficient sample was available, and duplicate when sample mass was limiting. Precision is reported as standard error of the mean.

\subsection{Statistics}

We performed the Shapiro-Wilk and Bartlett tests to determine normality and heteroskedasticity, respectively, for all data except spectroscopy data. For all analyses, the conditions for using parametric tests were not met, so we used the non-parametric Wilcoxon signed rank sum test to compare between the CC and NCC treatments.

\section{Results}

\subsection{Mass, Carbon, and Nitrogen Distribution in Aggregates}

\subsubsection{Size Separated Aggregates}

The mass distribution of size separated (wet sieved) soil aggregates was significantly different between CC and NCC only in the 250-2000 $\mu \mathrm{m}(p<0.05)$ and $<53 \mu \mathrm{m}(p<0.1)$ size fractions (Figure 1A). In the top $10 \mathrm{~cm}$, soil was mainly composed of larger microaggregates $(53-250 \mu \mathrm{m} ; 43.8 \%$ total, $44.5 \%$ CC and $43.0 \%$ NCC; $p=0.48)$ and smaller macroaggregates $(250-2000 \mu \mathrm{m} ; 39.4 \%$ total; $37.7 \%$ CC and $41.1 \%$ NCC; $p=0.03)$. About $13 \%$ of soil mass was in microaggregates $(<53 \mu \mathrm{m} ; 14.1 \% \mathrm{CC}, 12.7 \% \mathrm{NC}$, $13.4 \%$ total; $p=0.057), \sim 3 \%$ in large macroaggregates ( $>2000 \mu \mathrm{m} ; 3.6 \%$ for CC; $3.0 \%$ for NCC; and $3.3 \%$ total; $p=0.34$ ) and $\sim 0.1 \%$ in the floating light fraction (Figure $1 \mathrm{~A} ; 0.1 \%$ CC; $0.1 \mathrm{NCC} ; 0.1 \%$ total; $p=0.88$ ).

Carbon distribution was similar to mass distribution, with the majority of $\mathrm{C}$ contained in aggregates between 53 and $2000 \mu \mathrm{m}$ (Figure 1C). Carbon distribution was not significantly different between NCC and $C C$ treatments when comparing within an aggregate size fraction (Figure 1C). The $C$ proportion of NCC was significantly different between 53 to $250 \mu \mathrm{m}$ and 250 to $2000 \mu \mathrm{m}$ but no difference in C allocation was observed between these two fractions with CC (Figure 1C). The free light fraction (FLF) and large macroaggregates $(>2000 \mu \mathrm{m})$ had higher $C$ content (mass percentage basis, Table 1 ) than small microaggregates $(<53 \mu \mathrm{m})$, and thus even the small masses of the $>2000 \mu \mathrm{m}$ and FLF (Figure 1A) substantially contributed to the total $C$ pool (Figure 1C). There were no significant differences between the $\% \mathrm{C}$ in any of the size fractions or in the bulk soil between CC and NCC treatments $(p>0.1)$.

C:N ratios were not significantly different between CC and NCC soil for any aggregate size class or bulk soil ( $p>0.1$; Table 1). C:N ratios in the FLF were $>20$, indicating dominance of less degraded plant material, while the $\mathrm{C}: \mathrm{N}$ ratio of all aggregate size fractions ranged between 9.8 and 12.7, indicating relatively processed organic matter compared to FLF.

Soil bulk chemical composition was similar between CC and NCC soils. Elemental composition was typical for this soil type with $\sim 24 \% \mathrm{Si}$ and $5 \% \mathrm{Fe}$ and $\mathrm{Al}$ (Table 1). Elemental composition generally had little variation between aggregate sizes except for $\mathrm{S}$ content, which increased as aggregate size decreased (Table 1). 
Table 1. Elemental and isotopic composition of size separated aggregates from 0 to $10 \mathrm{~cm}$ depth of cover crop and no cover crop fields.

\begin{tabular}{|c|c|c|c|c|c|c|c|c|c|c|c|c|c|c|c|}
\hline & & C & $\delta^{13} \mathrm{C}$ & $\mathbf{N}$ & $\delta^{15} \mathrm{~N}$ & $\mathrm{C} / \mathrm{N}$ & Mg & Al & $\mathrm{Si}$ & $\mathbf{P}$ & $S$ & $\mathbf{K}$ & $\mathrm{Ca}$ & Mn & $\mathrm{Fe}$ \\
\hline & & $\%$ & $\%$ & $\%$ & $\%$ & & $\%$ & $\%$ & $\%$ & $\%$ & Ppm & $\%$ & $\%$ & Ppm & $\%$ \\
\hline \multirow{2}{*}{ Bulk Soil } & $\mathrm{NCC}^{1}$ & $1.00(2)^{3}$ & $-25.2^{* *}$ & 0.11 & $4.1(2)$ & 11.1 & 3.4 & 5.3 & 24.1 & 0.0 & 270 & 1.3 & 0.8 & 1010 & 5.2 \\
\hline & $\mathrm{CC}^{2}$ & $1.04(4)$ & $-25.6^{* *}$ & 0.11 & 3.8 & $11.3(5)$ & 3.6 & 5.4 & 24.6 & 0.1 & 280 & 1.3 & 0.8 & 1030 & 5.2 \\
\hline \multirow{2}{*}{$>2000 \mu \mathrm{m}$} & NCC & $1.28(6)$ & $-25.7(4)$ & 0.15 & $4.2(6)$ & $9.8(2)$ & 2.9 & 4.8 & 21.7 & 0.0 & 250 & 1.2 & 0.8 & 920 & 5.0 \\
\hline & $\mathrm{CC}$ & $1.81(29)$ & $-26.7(4)$ & $0.19(2)$ & $4.1(3)$ & $11.1(6)$ & 3.1 & 4.7 & 21.0 & 0.0 & 260 & 1.1 & 0.7 & 900 & 4.8 \\
\hline \multirow{2}{*}{ 250-2000 $\mu \mathrm{m}$} & NCC & $1.24(5)$ & $-25.1^{* *}$ & 0.12 & $6.5(6)$ & $12.2(2)$ & 1.8 & 4.0 & 19.5 & 0.0 & 289 & 1.1 & 0.8 & 951 & 5.4 \\
\hline & $\mathrm{CC}$ & $1.25(4)$ & $-25.4^{* *}$ & 0.12 & $5.9(3)$ & $12.6(2)$ & 3.2 & 5.0 & 22.3 & 0.0 & 250 & 1.2 & 0.8 & 949 & 5.5 \\
\hline \multirow{2}{*}{$53-250 \mu \mathrm{m}$} & $\mathrm{NCC}$ & $0.94(2)$ & -25.1 & 0.09 & $6.8(5)$ & $11.7(2)$ & 3.1 & 5.0 & 22.2 & 0.0 & 419 & 1.2 & 0.8 & 918 & 4.9 \\
\hline & $\mathrm{CC}$ & $1.01(2)$ & -25.3 & 0.1 & $6.1(4)$ & $12.3(3)$ & 3.1 & 4.8 & 21.7 & 0.0 & 403 & 1.2 & 0.8 & 909 & 4.8 \\
\hline \multirow{2}{*}{$<53 \mu \mathrm{m}$} & $\mathrm{NCC}$ & $1.09(4)$ & -25.3 & 0.13 & $5.1(4)$ & $9.9(2)$ & 3.4 & 5.9 & 24.1 & 0.1 & 621 & 1.2 & 0.8 & 1168 & 5.5 \\
\hline & $\mathrm{CC}$ & 1.07 & -25.4 & 0.13 & $4.6(5)$ & $10.0(2)$ & 3.1 & 5.5 & 22.1 & 0.1 & 601 & 1.2 & 0.8 & 1163 & 5.5 \\
\hline \multirow{2}{*}{ FLF } & $\mathrm{NCC}$ & 27.3 & -22.4 & 1.38 & 1.2 & 23.2 & & & & & & & & & \\
\hline & $\mathrm{CC}$ & 26.0 & -27.2 & 1.22 & -0.2 & 25.8 & & & & & & & & & \\
\hline
\end{tabular}

different at $p<0.1$ while ${ }^{* *}$ denotes that NCC and CC are significantly different at $p<0.05$. 

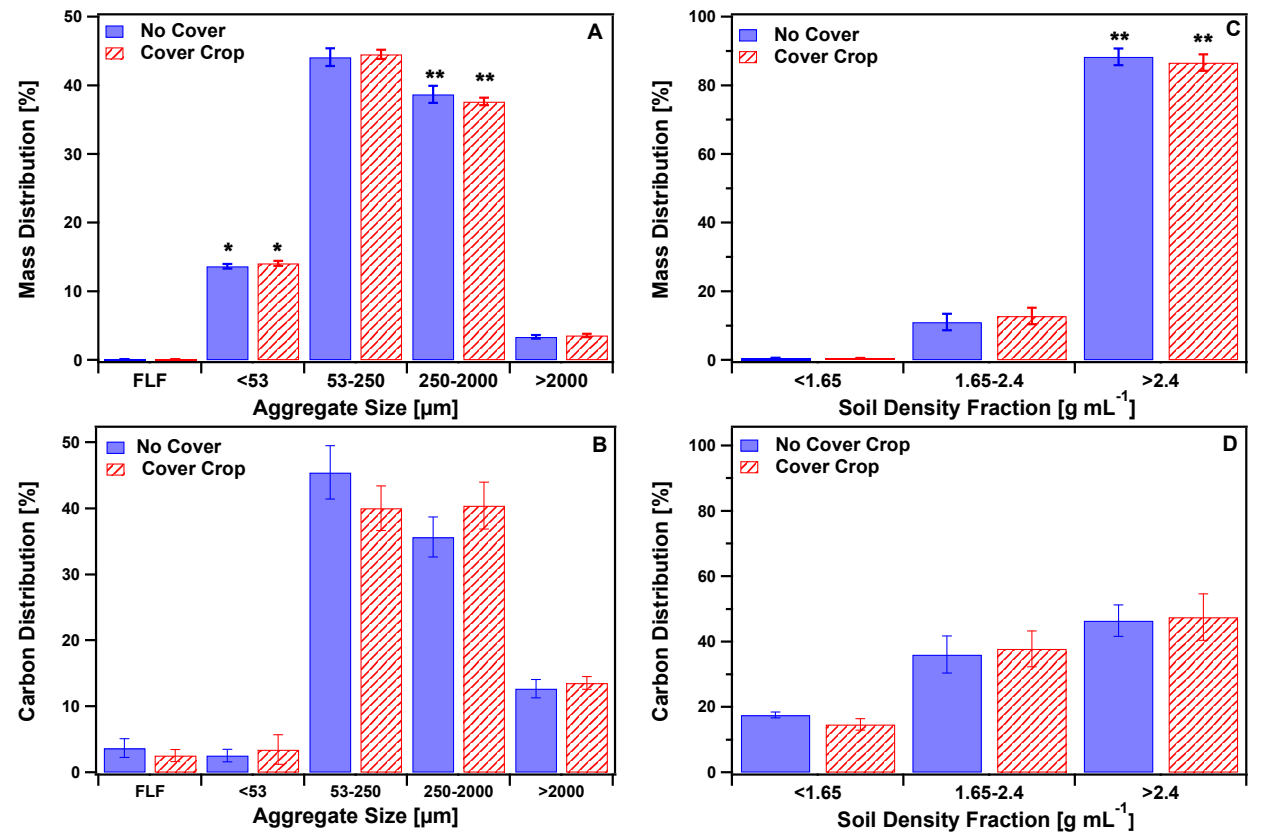

Figure 1. (A) Mass distribution in size separated aggregates; (B) carbon distribution in size separated aggregates; (C) mass distribution in density separated aggregates; (D) carbon distribution in density separated aggregates. Error bars represent \pm standard error. FLF is the free light fraction. Asterisk represent $p$ values according to the following: ${ }^{*}(p<0.1){ }^{* *}(p<0.05)$.

\subsubsection{Density Separated Aggregates}

The dense fraction $\left(>2.4 \mathrm{~g} \mathrm{~cm}^{-3}\right)$ contributed $>80 \%$ of soil mass in both NCC and CC soils (Figure 1B) while the remainder of the soil mass was dominated by intermediate density aggregates with little mass in the light density fraction. The $C$ content (mass $C$ per mass dry soil basis) decreased as density fraction increased from light $(26-38 \% \mathrm{C})$ to intermediate $(2-7 \% \mathrm{C})$ to heavy $(0.4-0.6 \% \mathrm{C})$ (Table 2). The light fraction contributed $15-18 \%$ of total soil C pool (Figure 1D) despite making up only $\sim 0.5 \%$ of the soil mass (Figure 1C).

\subsubsection{Sequential Size-Density Separation}

Size-separated aggregate fractions were subsequently separated by density to determine $C$ associations with mineral fractions within each aggregate size class. The mass distribution between density separations was similar across samples with $<1 \%$ in the light fraction, $7-20 \%$ in the intermediate fraction, and 79-93\% in the dense fraction (Table 2).

Carbon content of bulk soil was $\sim 400 \mathrm{mg} \mathrm{kg}^{-1}$ higher in CC than in NCC, but this difference was not statistically significant (Table 1). The $C$ content of the light density fraction of each size fraction was higher in CC than in NCC except for the $<53 \mu \mathrm{m}$ size fraction (Table 2). In the $<53 \mu \mathrm{m}$ size fraction, the intermediate density fraction had $7.2 \%$ in CC compared to $5.0 \%$ C in NCC (Table 2). Density separation was not performed on $>2000 \mu \mathrm{m}$ samples due to small mass recovery from wet sieving. 
Table 2. Mass distribution, carbon and nitrogen abundance, and isotopic composition of sequential size-density separated aggregates from 0 to $10 \mathrm{~cm}$ depth of cover crop and no cover crop soils.

\begin{tabular}{|c|c|c|c|c|c|c|c|}
\hline & Starting Material & $\begin{array}{c}\text { Density } \\
\mathrm{g} \mathrm{cm}^{-3}\end{array}$ & $\begin{array}{l}\mathrm{C} \\
\%\end{array}$ & $\begin{array}{c}\delta^{13} \mathrm{C} \\
\% o\end{array}$ & $\begin{array}{l}\mathbf{N} \\
\%\end{array}$ & $\begin{array}{c}\mathcal{\delta}^{15} \mathrm{~N} \\
\% \mathrm{o}\end{array}$ & $\mathrm{C} / \mathrm{N}$ \\
\hline $\mathrm{NCC}^{2}$ & Bulk Soil & $\begin{array}{c}<1.65 \\
1.65-2.4 \\
>2.4\end{array}$ & $\begin{array}{c}27(2)^{4} \\
4.6(6) \\
0.5\end{array}$ & $\begin{array}{l}-24.6(5) * \\
-24.8 * * \\
-24.9 * *\end{array}$ & $\begin{array}{c}1.4 \\
0.4(2) \\
0.1\end{array}$ & $\begin{array}{c}1.6(4) \\
2.8 \\
4.1(2) * *\end{array}$ & $\begin{array}{c}21.8 * \\
12.4(2) \\
7.7 *\end{array}$ \\
\hline $\mathrm{CC}^{3}$ & Bulk Soil & $\begin{array}{c}<1.65 \\
1.65-2.4 \\
>2.4\end{array}$ & $\begin{array}{c}26(2) \\
4.3(7) \\
0.5\end{array}$ & $\begin{array}{l}-25.7(2)^{*} \\
-25.3 * * \\
-25.0 * *\end{array}$ & $\begin{array}{l}1.6 \\
0.4 \\
0.1\end{array}$ & $\begin{array}{c}1.2(2) \\
2.9 \\
4.3^{* *}\end{array}$ & $\begin{array}{c}19.5(6) * \\
12.6 \\
7.7 *\end{array}$ \\
\hline NCC & $250-2000 \mu \mathrm{m}$ & $\begin{array}{c}<1.65 \\
1.65-2.4 \\
>2.4\end{array}$ & $\begin{array}{l}26 \\
2.6 \\
0.6\end{array}$ & $\begin{array}{c}23.7 \\
-24.9 \\
-24.8 \\
\end{array}$ & $\begin{array}{l}1.5 \\
0.2 \\
0.1\end{array}$ & $\begin{array}{l}0.8 \\
3.0 \\
4.5 \\
\end{array}$ & $\begin{array}{c}20.5 \\
12.8 \\
9.9\end{array}$ \\
\hline $\mathrm{CC}$ & $250-2000 \mu \mathrm{m}$ & $\begin{array}{c}<1.65 \\
1.65-2.4 \\
>2.4\end{array}$ & $\begin{array}{l}32 \\
2.5 \\
0.6\end{array}$ & $\begin{array}{l}-24.9 \\
-25.5 \\
-25.0\end{array}$ & $\begin{array}{l}1.9 \\
0.2 \\
0.1\end{array}$ & $\begin{array}{l}0.2 \\
2.6 \\
4.0\end{array}$ & $\begin{array}{c}19.4 \\
12.4 \\
9.8\end{array}$ \\
\hline NCC & $53-250 \mu \mathrm{m}$ & $\begin{array}{c}<1.65 \\
1.65-2.4 \\
>2.4\end{array}$ & $\begin{array}{l}29 \\
2.1 \\
0.4\end{array}$ & $\begin{array}{l}-24.1 \\
-24.9 \\
-24.7 \\
\end{array}$ & $\begin{array}{l}1.6 \\
0.2 \\
0.1\end{array}$ & $\begin{array}{l}1.9 \\
3.1 \\
4.7 \\
\end{array}$ & $\begin{array}{c}21.5 \\
12.1 \\
8.6\end{array}$ \\
\hline $\mathrm{CC}$ & $53-250 \mu \mathrm{m}$ & $\begin{array}{c}<1.65 \\
1.65-2.4 \\
>2.4\end{array}$ & $\begin{array}{l}38 \\
2.3 \\
0.4\end{array}$ & $\begin{array}{l}-24.0 \\
-25.2 \\
-24.9\end{array}$ & $\begin{array}{l}2.0 \\
0.2 \\
0.1\end{array}$ & $\begin{array}{c}-0.8 \\
2.9 \\
3.4\end{array}$ & $\begin{array}{c}22.2 \\
12.3 \\
8.3\end{array}$ \\
\hline NCC & $<53 \mu \mathrm{m}$ & $\begin{array}{c}<1.65 \\
1.65-2.4 \\
>2.4\end{array}$ & $\begin{array}{c}36 \\
5.0(7) \\
0.5\end{array}$ & $\begin{array}{c}-25.3 \\
-25.1^{* *} \\
-24.9\end{array}$ & $\begin{array}{l}1.7 \\
0.4 \\
0.1\end{array}$ & $\begin{array}{c}2.4 \\
3.0^{* *} \\
4.2\end{array}$ & $\begin{array}{c}21.7(4) \\
13.7(2)^{* *} \\
7.2\end{array}$ \\
\hline $\mathrm{CC}$ & $<53 \mu \mathrm{m}$ & $\begin{array}{c}<1.65 \\
1.65-2.4 \\
>2.4\end{array}$ & $\begin{array}{c}28(6) \\
7(1) \\
0.5\end{array}$ & $\begin{array}{c}-25.6(4) \\
-25.4^{* *} \\
-24.9\end{array}$ & $\begin{array}{c}1.3(3) \\
0.6 \\
0.1\end{array}$ & $\begin{array}{l}1.3(8) \\
3.1^{* *} \\
4.4(2)\end{array}$ & $\begin{array}{c}25.3(4) \\
14.8(2) \\
7.3\end{array}$ \\
\hline
\end{tabular}

${ }^{1}$ Density separation performed using sodium polytungstate; ${ }^{2}$ No cover crop; ${ }^{3}$ Cover crop; ${ }^{4}$ Values in parentheses indicate standard error, no parentheses indicate an error of unity ${ }^{*}$ NCC and CC are significantly different at $p<0.1 ;{ }^{* *}$ NCC and CC are significantly different at $p<0.05$. Statistical significance was determined using a Wilcoxon test. 


\subsection{Carbon and Nitrogen Isotopes}

Bulk soil under CC had more negative $\delta^{13} \mathrm{C}(-25.6 \%)$ compared to NCC $(-25.2 \%)(p<0.05$, Table 1). Although $\delta^{13} \mathrm{C}$ become more similar between NCC and CC as aggregate size decreases, $\delta^{13} \mathrm{C}$ in CC remains lower than NCC in all size fractions, and is significantly different in the $250-2000 \mu \mathrm{m}$ fraction $(p<0.05$, Table 1$)$. In the FLF, soil with CC had $\delta^{13} \mathrm{C} 4.8 \%$ o lower than NCC soil (Table 1 ) but due to small sample recovery this value was determined based on a composite of replicate samples, and thus statistical tests do not provide additional information. In density separated bulk soil, $\delta^{13} \mathrm{C}$ of CC soil was lower (more negative) than NCC soil in all three density fractions; however, the $\delta^{13} \mathrm{C}$ values became more similar as density increased from $1.1 \%$ in $<1.65 \mathrm{~g} \mathrm{~cm}^{-3}$ fraction to $0.5 \%$ o in the $1.65-2.4 \mathrm{~g} \mathrm{~cm}^{-3}$ fraction to $0.1 \%$ in the $>2.4 \mathrm{~g} \mathrm{~cm}^{-3}$ fraction (Table 2).

$\delta^{13} \mathrm{C}, \delta^{15} \mathrm{~N}$, and C:N ratio were significantly different between CC and NCC in the $1.65-2.4 \mathrm{~g} \mathrm{~cm}^{-3}$ fraction of small microaggregates $(<53 \mu \mathrm{m})$ (Table 2). Cover crop resulted in a $\delta^{13} \mathrm{C}$ value $0.3 \%$ o more negative compared to NCC, an increase of $0.1 \%$ in $\delta^{15} \mathrm{~N}$, and an increase in C:N ratio of 1.1.

Lower $\delta^{15} \mathrm{~N}$ values are consistent with an $\mathrm{N}$ fixation signal that could be attributed to the presence of legumes in CC. However, in the 1.65-2.4 $\mathrm{g} \mathrm{cm}^{-3}$ fraction of small microaggregates $(<53 \mu \mathrm{m})$ and $>2.4 \mathrm{~g} \mathrm{~cm}^{-3}$ fraction of bulk soil, $\delta^{15} \mathrm{~N}$ values were higher in CC than NCC soils (Table 2). Within a set of density fractions, $\delta^{15} \mathrm{~N}$ values always increased with increasing density (Table 2).

\subsection{X-ray Absorption Spectroscopy}

\subsubsection{Carbon NEXAFS Spectroscopy}

Carbon K-edge NEXAFS spectra of CC and NCC bulk soil were characterized by strong aromatic $(285 \mathrm{eV})$ and carboxyl $(288.5 \mathrm{eV})$ resonances, and also contained some carbonate signal $(290.2 \mathrm{eV})$ (Figure 2). Spectra collected on size-separated microaggregates ( $<53$ and 53-250 $\mu \mathrm{m}$ size fractions) are similar between CC and NCC soils and also exhibited strong aromatic and carboxyl resonances with a small carbonate peak in the $<53 \mu \mathrm{m}$ fraction (Figure 2). In both macroaggregate size fractions, a shifted and more intense phenolic $(286.7 \mathrm{eV})$ resonance is observed in CC compared to NCC samples in addition to similar aromatic and carboxyl peaks (Figure 2).

Intermediate and heavy density fractions of bulk soil and stepwise size-density fractionated soil had similar C NEXAFS spectra between CC and NCC treatments (Figure 3). Compared to bulk soil samples, the intermediate density samples showed a stronger aliphatic resonance at $287.4 \mathrm{eV}$ (Figures 2 and 3). In the dense fraction of the 250-2000 $\mu \mathrm{m}$ size fraction, CC resulted in a stronger aliphatic resonance relative to NCC (Figure 3). 


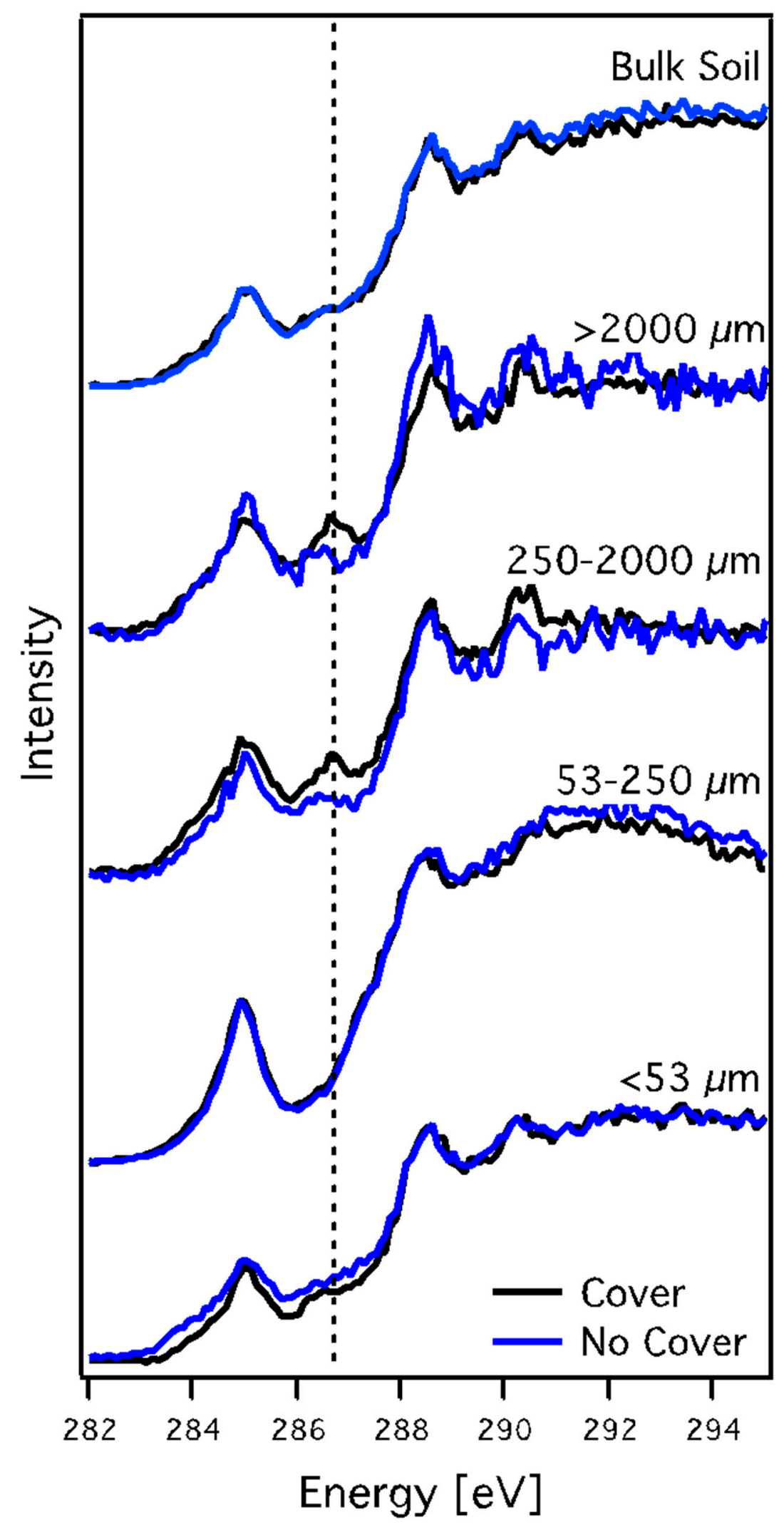

Figure 2. Carbon NEXAFS spectra of bulk soil and size-separated aggregates from soil with (black lines) and without (blue lines) cover crop. Dashed line at $286.7 \mathrm{eV}$ highlights the more intense and shifted phenolic peak in macroaggregates from cover crop soil. 

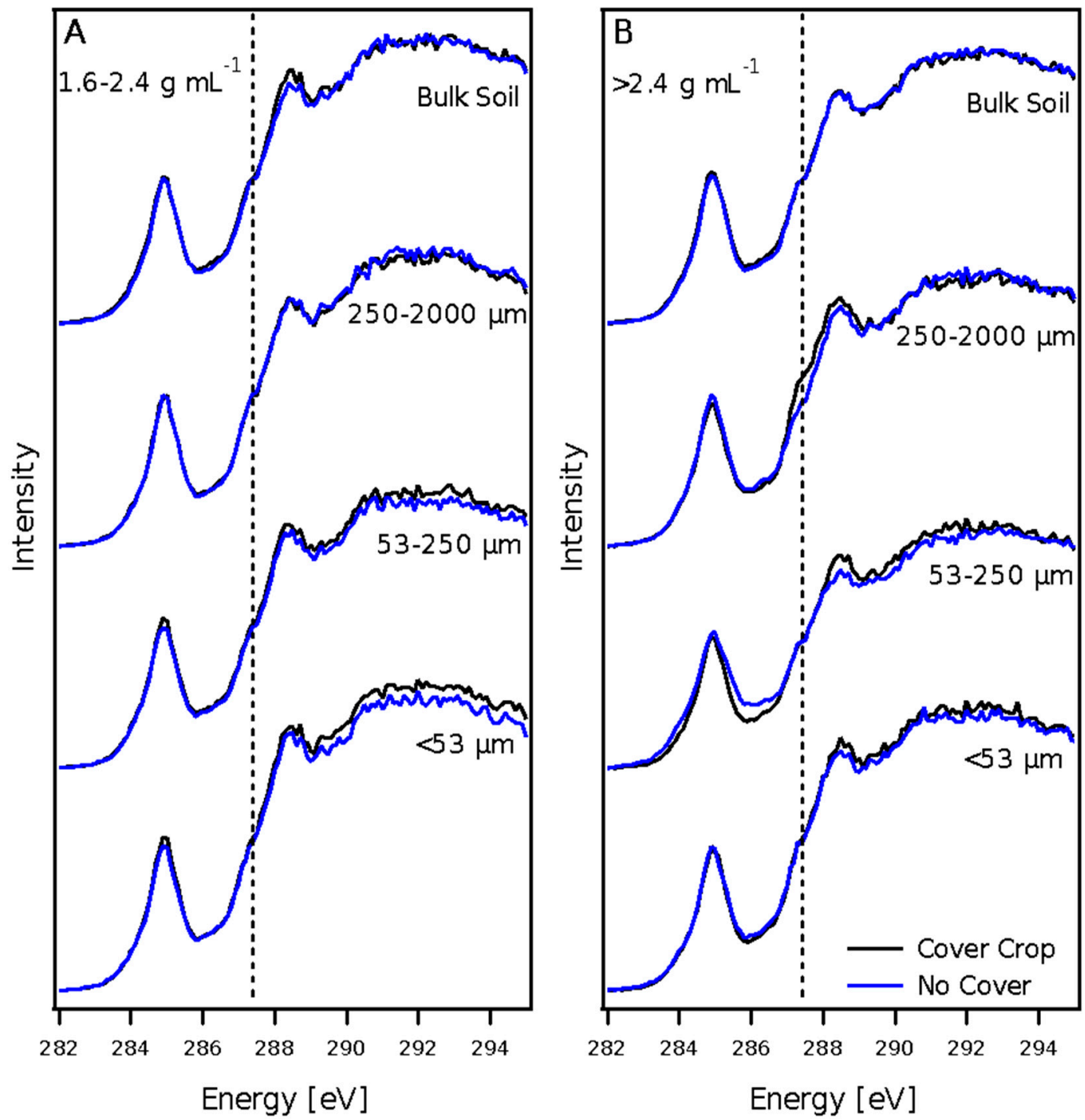

Figure 3. Carbon NEXAFS spectra of (A) intermediate density $\left(1.65-2.4 \mathrm{~g} / \mathrm{mL}^{-1}\right)$ and $(\mathbf{B})$ heavy density $\left(>2.4 \mathrm{~g} / \mathrm{mL}^{-1}\right)$ fractions of bulk soil and sequential size-density separated samples. Black lines indicate the soil with the cover crop, and blue lines indicate no cover crop.

\subsubsection{Fe K-Edge EXAFS Spectroscopy}

Iron EXAFS spectra of intermediate and heavy density fractions of bulk soil from CC and NCC soils show that Fe mineralogy is similar (Figure 4, Table 3). The Fe pool is composed of $17-21 \%$ oxide (fit with goethite standard) across samples (Table 3), while Fe in silicate minerals makes up the remainder of the Fe pool. Intermediate density fractions contain Fe in minerals more similar to nontronite (Fe-rich smectite) and phlogopite (Mg-rich mica) than the heavy density fraction, which has Fe in minerals more similar to hornblende (amphibole) and vermiculite (swelling, partially weathered phlogopite and/or biotite) (Table 3). However, the presence of cover crop had little effect on Fe mineralogy as observed by Fe K-edge EXAFS during the time period of this experiment. 


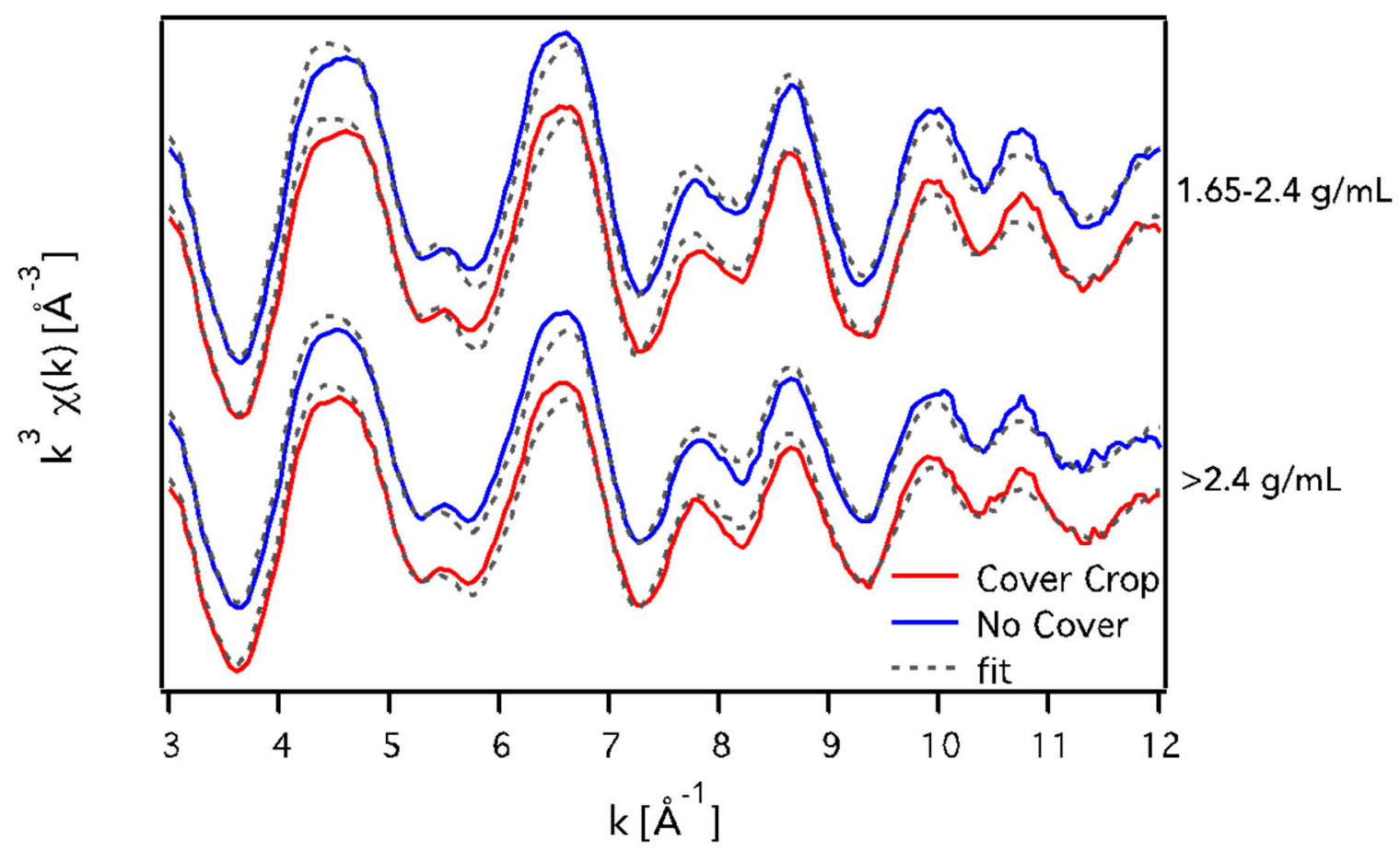

Figure 4. Fe K-edge $\mathrm{k}^{3}$ weighted EXAFS spectra of intermediate $\left(1.65-2.4 \mathrm{~g} / \mathrm{mL}^{-1}\right)$ and heavy $\left(>2.4 \mathrm{~g} / \mathrm{mL}^{-1}\right)$ soil density fractions from no cover (blue lines) and cover crop (red lines) treatments. Grey dashed lines indicate the least squares best fit for each sample (see Table 3 for fit results).

Table 3. Fe EXAFS linear combination fit results.

\begin{tabular}{cccccccc}
\hline Treatment & Density $\left(\mathbf{g ~ c m}^{-3}\right)$ & Goethite & Hornblende & Nontronite & Phlogopite & Vermiculite & $\mathbf{x}^{\mathbf{2}}$ \\
\hline No Cover & $1.65-2.4$ & $17 \%$ & $23 \%$ & $43 \%$ & $12 \%$ & $6 \%$ & 0.43 \\
Cover Crop & $1.65-2.4$ & $18 \%$ & $25 \%$ & $40 \%$ & $14 \%$ & $4 \%$ & 0.38 \\
\hline No Cover & $>2.4$ & $21 \%$ & $32 \%$ & $27 \%$ & $4 \%$ & $16 \%$ & 0.33 \\
Cover Crop & $>2.4$ & $19 \%$ & $28 \%$ & $31 \%$ & $3 \%$ & $19 \%$ & 0.31 \\
\hline
\end{tabular}

\subsection{Chemical Extractions}

\subsubsection{Acid Ammonium Oxalate}

Oxalate extractable Fe was 6.4 and $6.8 \mathrm{mg} \mathrm{Fe}(\mathrm{g} \text { soil })^{-1}$ for CC and NCC soils, respectively, representing $12-13 \%$ of the total soil Fe pool (Table 1, Figure 5A). Oxalate extractable Fe was highest in the $<53 \mu \mathrm{m}$ size fraction in both CC and NCC treatments and lowest in the 53-250 $\mu \mathrm{m}$ size fraction, but ranged between 6 and $8 \mathrm{mg}$ Fe $\left(\mathrm{g}\right.$ soil) ${ }^{-1}$ for all size separated samples (Figure $\left.5 \mathrm{~A}\right)$. In dense fractions $\left(>2.4 \mathrm{~g} \mathrm{~cm}^{-3}\right)$ oxalate extractable Fe was higher in NCC bulk soil, lower in NCC $<53 \mu \mathrm{m}$, and similar between NCC and CC in the 53-250 and 250-2000 $\mu \mathrm{m}$ size fractions (Figure 5B). Oxalate extractions were not performed on intermediate fractions due to lack of available sample. 

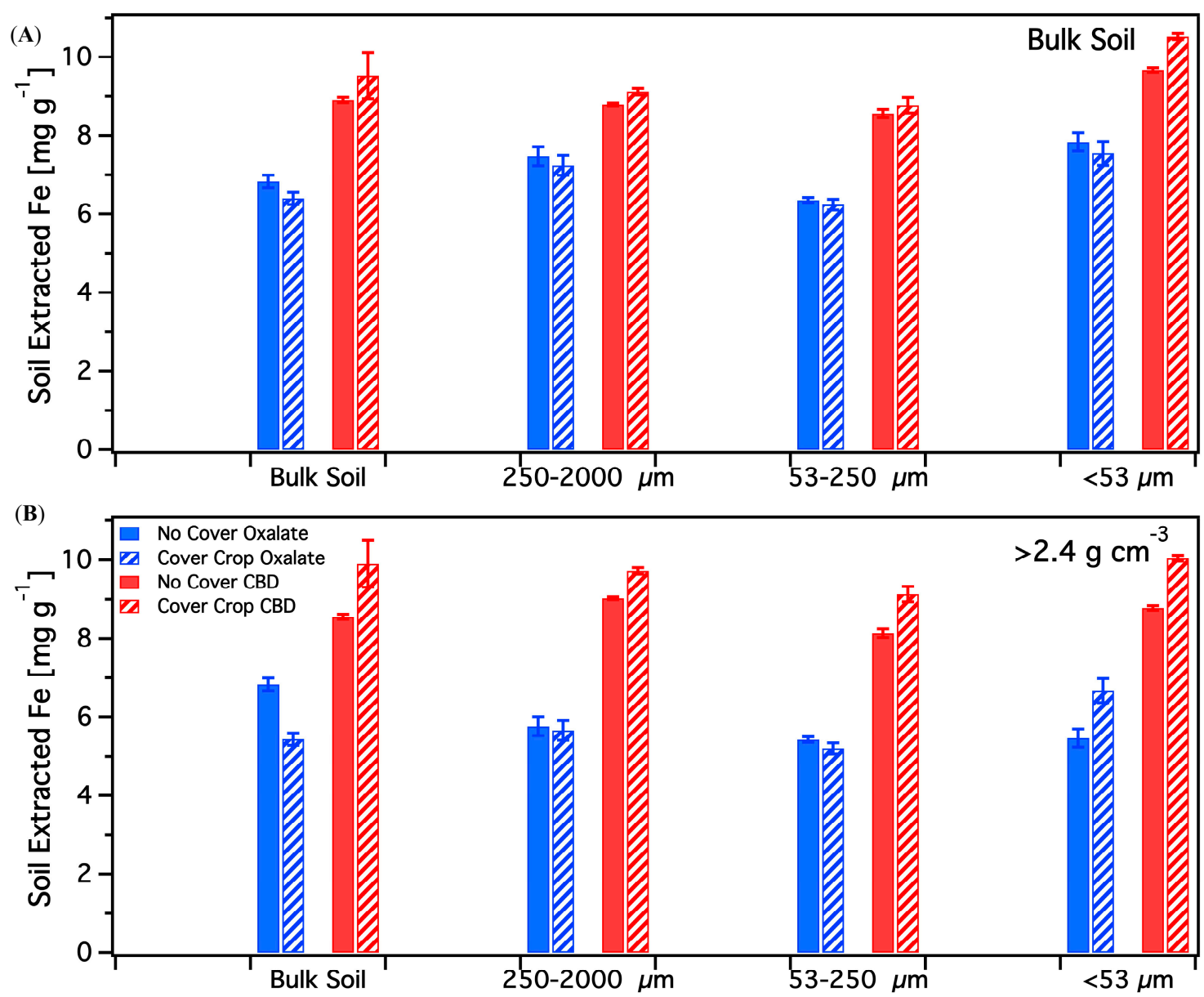

Figure 5. Acid ammonium oxalate (blue bars) and citrate-bicarbonate-dithionite (red bars) extractable Fe for no cover crop (solid bars) and cover crop (dashed bars) soils. Values are expressed as mg Fe per g dry soil mass for (A) bulk soil and aggregate size fractions, and (B) the heaviest density fraction $\left(>2.4 \mathrm{~g} \mathrm{~cm}^{-3}\right)$ of bulk soil and aggregate size fractions. Error bars represent \pm standard error. Differences between cover crop and no cover crop were significant for the CBD extraction of 250-2000 $\mu \mathrm{m}$ size fraction $(p=0.1)$ and for the oxalate extraction of bulk soil and bulk $>2.4 \mathrm{~g} \mathrm{~cm}^{-3}$ density fraction $(p=0.01)$.

\subsubsection{Citrate-Bicarbonate-Dithionite}

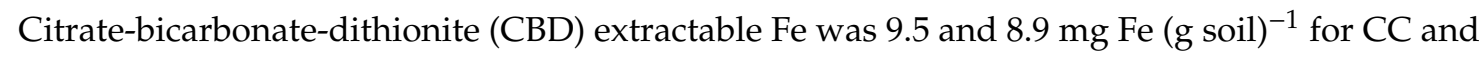
NCC bulk soils, respectively. Aggregate size fractions had higher CBD extractable Fe in CC compared to NC soils. Dense fraction CBD extractable Fe was higher in CC compared to NC soils in bulk soil and every size fraction (Figure 5).

\section{Discussion}

\subsection{Cover Crop Effect on Carbon Inputs}

The gross results suggest that the average $C$ content of CC bulk soil was $\sim 400 \mathrm{mg} \mathrm{kg}^{-1}$ higher than NCC in the top $10 \mathrm{~cm}$ measured during a single season of CC (Table 1), but this difference was not statistically significant. We hypothesized that new C inputs from CC would, at least initially, be incorporated into macroaggregates, which are less stable and have faster turnover times than microaggregates [8]. Multiple lines of evidence point to dynamic $\mathrm{C}$ cycling in both micro-and macroaggregates in our site, despite a relatively small and statistically insignificant difference in bulk SOC content or aggregate distribution (Figure 1). This pattern may be explained by the multiple 
influences of plant roots on soil aggregate destruction and formation which have been extensively reviewed [26-28].

Large macroaggregate $(>2000 \mu \mathrm{m})$ bulk SOC content and the C:N ratio were higher and $\delta^{13} \mathrm{C}$ was more negative in CC compared to NC (Table 1). Although these differences were not statistically significant at the $p<0.1$ level, together they indicate that fresh plant inputs in CC are stabilized in macroaggregates. Carbon NEXAFS data indicated that CC macroaggregates had increased phenolic character relative to NCC (Figure 3), providing spectroscopic evidence for the impact of CC on SOC in macroaggregates. Plant roots both destroy aggregates [29] and provide root fragments, mucin, and exudates that act as nucleation points and binders for aggregate formation [30,31]; thus they are likely a major contributor of additional plant material into CC macroaggregates. Higher frequency drying-wetting cycles due to increased transpiration in CC could also increase macroaggregate turnover rate compared to NCC [32]. Importantly, the effects of plant roots are also dependent on soil mineralogy [33], but this was not varied in the experiment. Overall it appears that CC roots promoted faster macroaggregate turnover but with limited net change in aggregation or $\mathrm{C}$ content over a short time period of CC.

The small macroaggregate fraction $(250-2000 \mu \mathrm{m})$ had lower $\delta^{13} \mathrm{C}$ in CC compared to NCC $(p<0.05)$, indicating incorporation of less processed organic matter (Table 1). Increased phenol resonance in the C NEXAFS spectrum of CC compared to NCC (Figure 3) further indicated that although the amount of $C$ did not significantly change with $C C$, the $C$ pool was actively cycled and $C$ chemical composition changed to reflect more plant-like character in small macroaggregates.

\subsection{Aggregate Dynamics}

These results are consistent with the aggregate hierarchy framework where macroaggregates are sensitive to management, especially root growth $[4,14]$ and possibly mechanical soil disturbances related to planting CC. Our results provide direct spectroscopic evidence that macroaggregates $(>250 \mu \mathrm{m})$ incorporated plant material within a single cover cropping season (Figure 2). Interestingly, little variation in $\mathrm{C}$ chemical composition was observed in density fractions across bulk soil, macroaggregates, and microaggregates (Figure 3). Thus, we propose that, at least initially, changes in C chemical composition following CC are largely a function of incorporation of particulate $\mathrm{C}$ into macroaggregates and not alteration of $\mathrm{C}$ in mineral fractions. Rapid incorporation of particulate $\mathrm{C}$ into macroaggregates is further supported by the similarity in the mass of FLF and $<1.65 \mathrm{~g} \mathrm{~cm}^{-3}$ fractions between CC and NCC despite additional plant inputs with CC (Table 1, Table 2).

Cover crop roots also may alter Fe mineralogy in bulk soil and aggregates through production of organic acids [15] or polysaccharides [34]. In bulk soil samples, CC slightly increased total extractable Fe content (CBD extraction) in the bulk soil and $<53 \mu \mathrm{m}$ microaggregates while no change was observed in the poorly crystalline (oxalate extraction) Fe pool (Figure 5A). In the dense fraction $\left(>2.4 \mathrm{~g} \mathrm{~cm}^{-3}\right.$ ), CBD-extractable Fe was higher in bulk soil and all stepwise size-density fractions (Figure 5B). However, the dense fraction oxalate-extractable Fe was lower with CC in bulk soil and higher in the dense fraction of small microaggregates (Figure 5B). The decrease in oxalate-extractable (poorly crystalline) Fe minerals with CC could be due to dissolution from additional root exudates with CC [24] or due to the presence of more recent aggregates with fewer organic-Fe complexes and less weathered primary minerals. The CBD extractable Fe content compares well with Fe EXAFS data, indicating that the soil Fe pool is comprised of $\sim 18 \%$ Fe-oxides. Changes in Fe mineral crystallinity or extractability could be affected by increased organic acids interacting with Fe minerals $[15,35,36]$. Extractable Fe increased with CC in the dense fraction of bulk soil and both macroaggregates and microaggregates, perhaps due to an increase in polysaccharide production in the dense fraction [34].

The impact of CC on C composition in aggregates was detected after only a single season of CC. Based on this work, we propose a conceptual model of SOC replacement within aggregates driven by plant roots (Figure 6). The presence of additional roots drives aggregate turnover through physical aggregate breakup and increased $C$ mineralization due to root exudate sugars and ligands [15]. 
However, root fragments and fungal hyphae also provide nuclei for aggregate reformation [37]. During macroaggregate reformation following tillage and root growth but before the introduction of summer irrigated tomato crop, bulk SOC content increased slightly in the $>2000 \mu \mathrm{m}$ macroaggregates under CC (Table 1), and $\delta^{13} \mathrm{C}, \mathrm{C}: \mathrm{N}$ ratios (Tables 1 and 2), and C NEXAFS (Figure 2) results all show a dynamic $C$ pool where some $C$ is replaced with plant root inputs. This idea is supported by the preferential retention of root compared to aboveground OM [8]. Density fractionation and $\delta^{13} \mathrm{C}$ results show that changes in bulk soil and macroaggregate $C$ are primarily particulate $\left(<1.65 \mathrm{~g} \mathrm{~cm}^{-3}\right)$ and, to a lesser extent, mineral-associated $\left(1.65-2.4 \mathrm{~g} \mathrm{~cm}^{-3}\right)$, but no change in the dense fraction $\delta^{13} \mathrm{C}$ was observed (Table 2).

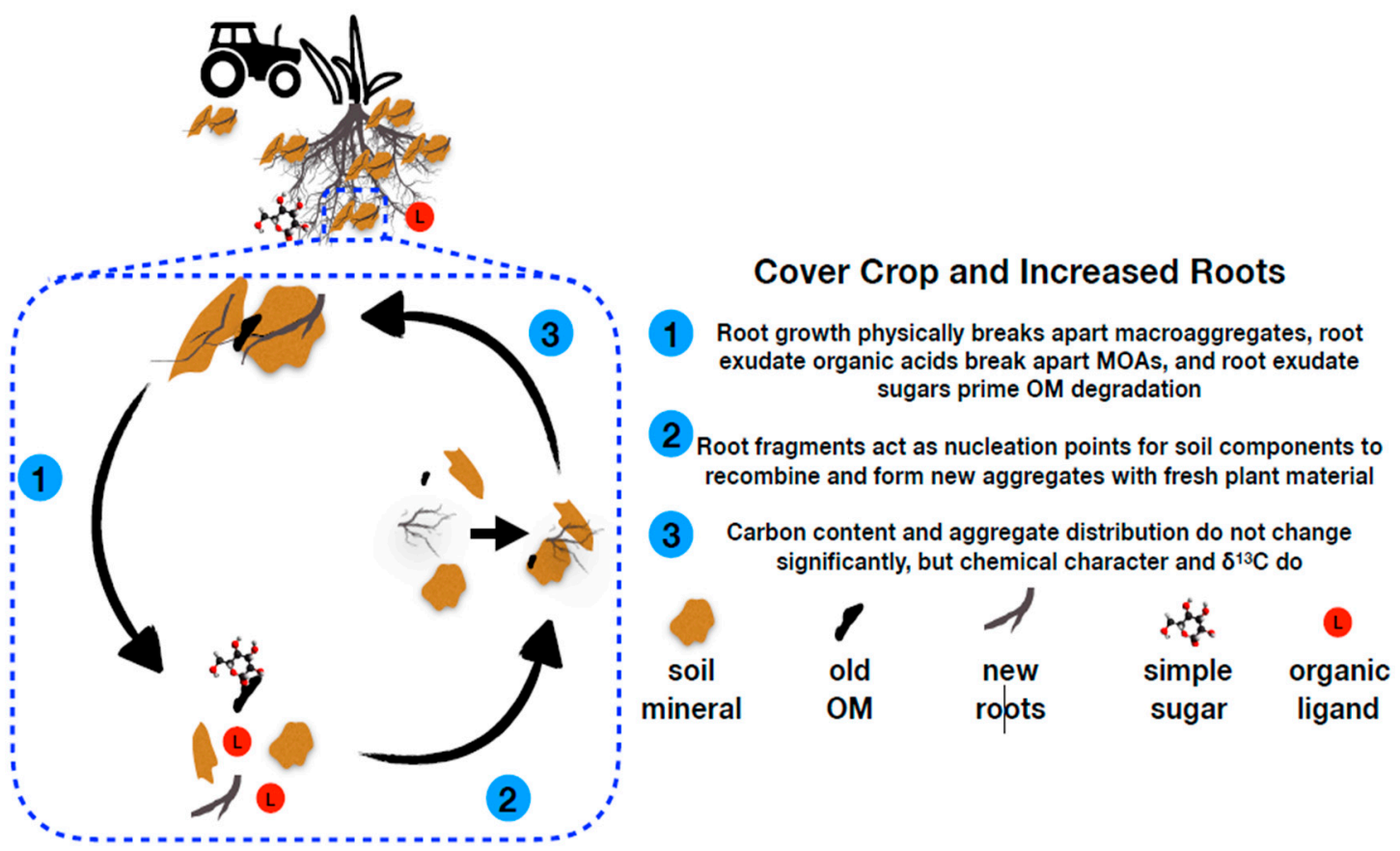

Figure 6. Conceptual model of the influence of cover crop roots on fresh carbon incorporation into macroaggregates. Root growth (and potentially the act of planting cover crop) physically breaks apart macroaggregates while organic acids disrupt mineral-organic associations (MOAs). These processes, combined with organic matter decomposition stimulated by root sugars, lead to enhanced carbon turnover in cover crop soil. However, carbon loss due to root exudates is balanced and slightly exceeded by input of additional root biomass. Although bulk carbon contents do not significantly change, cover crop accelerates carbon turnover in soil macroaggregates.

\section{Conclusions}

Size-separated microaggregates (53-250 and $<53 \mu \mathrm{m}$ ) had similar $\mathrm{C}$ content between CC and NCC soils, and $\delta^{13} \mathrm{C}$ values were lower in bulk soil and 250-2000 $\mu \mathrm{m}$ size fractions with CC (Table 1 ). Carbon NEXAFS spectra showed similar C chemical composition in CC and NC microaggregates (Figure 3). Based only on examining size-separated aggregates, little incorporation of new $\mathrm{C}$ occurred with CC relative to NCC soil. Stepwise size-density separation, however, provides a more detailed view of $C$ dynamics in microaggregates. In all density fractions of bulk soil $\delta^{13} C$ values were significantly lower in CC compared to NCC soils. One explanation for these responses is that CC root exudates [15] may liberate particulate $C$ from minerals, enriching $C$ content in the light fraction of $C C$ soil while providing potential for mineral (re)precipitation with fresh $C$ to produce higher $C$ content intermediate density fractions. This explanation is further supported by extraction results, where the proportion of poorly crystalline Fe (oxalate/CBD extractable) was $77 \%$ in NC bulk soil compared to $67 \%$ in CC bulk soil, indicating that CC may lead to increased Fe oxide crystallinity, likely through a combination of selective dissolution of less crystalline Fe oxides by root exudates (e.g., oxalate) and recrystallization 
through dissolution and precipitation reactions [38-40]. However, this explanation would require exudate transport into aggregates either through advection or diffusion, or root/hyphae penetration into aggregates.

Author Contributions: Conceptualization, M.V.S., N.A.B., D.R., K.M.S., P.S.N., S.C.Y., S.P. and E.L.B.; Methodology, M.K., Y.L., T.A.G. and P.S.N.; Investigation, M.V.S., N.A.B., D.R., A.G., T.H., A.R.M. and C.C.A.; Statistical Analyses, A.R.M., Y.L.; Resources, M.L.F., K.M.S., and S.C.Y.; Writing-Original Draft Preparation, M.V.S.; Writing-Review and Editing, M.V.S., P.S.N., W.J.R., N.A.B., S.C.Y., A.R.M., Y.L., T.A.G.; Visualization, M.V.S.; Supervision, P.S.N., S.C.Y.; Project Administration, S.C.Y.; Funding Acquisition, S.C.Y., P.S.N., E.L.B., K.M.S., A.A.B. All authors have read and agreed to the published version of the manuscript.

Funding: This research was funded by the University of California Office of the President CATALYST award and the EDGE Institute at UC Riverside.

Acknowledgments: We thank members of the UC CATALYST DroCaM team for help with sample collection. We also thank Sharon Bone, Ryan Davis, Matthew Lattimer, and Erik Nelson at SSRL, and Jay Dynes, Adam Gillespie, and Tom Regier at CLS for support at synchrotron beamlines. Portions of this research were carried out at the Stanford Synchrotron Radiation Lightsource, a Directorate of SLAC National Accelerator Laboratory and an Office of Science User Facility operated for the U.S. Department of Energy Office of Science by Stanford University. The project was funded by the UCOP Presidential Catalyst Award (CA-16-377706). Work at Lawrence Berkeley National Laboratory was supported by the U.S. Department of Energy, Office of Science, under Contract Number DE-AC02-05CH11231. S. Ying is supported by USDA NIFA Hatch Project CA-R-ENS-5151-H. Research described in this paper was performed at the Canadian Light Source, which is supported by the Canada Foundation for Innovation, Natural Sciences and Engineering Research Council of Canada, the University of Saskatchewan, the Government of Saskatchewan, Western Economic Diversification Canada, the National Research Council Canada, and the Canadian Institutes of Health Research.

Conflicts of Interest: The authors declare no conflict of interest. The funders had no role in the design of the study; in the collection, analyses, or interpretation of data; in the writing of the manuscript; or in the decision to publish the results.

\section{References}

1. Minasny, B.; Malone, B.P.; McBratney, A.B.; Angers, D.A.; Arrouays, D.; Chambers, A.; Chaplot, V.; Chen, Z.-S.; Cheng, K.; Das, B.S.; et al. Soil carbon 4 per mille. Geoderma 2017, 292, 59-86. [CrossRef]

2. Poeplau, C.; Don, A. Carbon sequestration in agricultural soils via cultivation of cover crops-A meta-analysis. Agric. Ecosyst. Environ. 2015, 200, 33-41. [CrossRef]

3. Mayer, A.; Hausfather, Z.; Jones, A.D.; Silver, W.L. The potential of agricultural land management to contribute to lower global surface temperatures. Sci. Adv. 2018, 4, eaaq0932. [CrossRef] [PubMed]

4. Tisdall, J.M.; Oades, J.M. Organic matter and water-stable aggregates in soils. J. Soil Sci. 1982, 33, 141-163. [CrossRef]

5. Rorick, J.D.; Kladivko, E.J. Cereal rye cover crop effects on soil carbon and physical properties in southeastern Indiana. J. Soil Water Conserv. 2017, 72, 260-265. [CrossRef]

6. Kabir, Z.; Koide, R.T. The effect of dandelion or a cover crop on mycorrhizal inoculum potential, soil aggregation and yield of maize. Agric. Ecosyst. Environ. 2000, 78, 167-174. [CrossRef]

7. Roberson, E.B.; Firestone, M.K.; Sarig, S. Cover Crop Management of Polysaccharide-Mediated Aggregation in an Orchard Soil. Soil Sci. Soc. Am. J. 1991, 55, 734-739. [CrossRef]

8. Kong, A.Y.Y.; Six, J. Tracing Root vs. Residue Carbon into Soils from Conventional and Alternative Cropping Systems. Soil Sci. Soc. Am. J. 2010, 74, 1201-1210. [CrossRef]

9. Kong, A.Y.Y.; Six, J. Microbial community assimilation of cover crop rhizodeposition within soil microenvironments in alternative and conventional cropping systems. Plant Soil 2012, 356, 315-330. [CrossRef]

10. Berhe, A.A.; Suttle, K.B.; Burton, S.D.; Banfield, J.F. Contingency in the direction and mechanics of soil organic matter responses to increased rainfall. Plant Soil 2012, 358, 371-383. [CrossRef]

11. Hall, S.J.; Berhe, A.A.; Thompson, A. Order from disorder: Do soil organic matter composition and turnover co-vary with iron phase crystallinity? Biogeochemistry 2018, 140, 93-110. [CrossRef]

12. Eusterhues, K.; Neidhardt, J.; Hädrich, A.; Küsel, K.; Totsche, K.U. Biodegradation of ferrihydrite-associated organic matter. Biogeochemistry 2014, 119, 45-50. [CrossRef]

13. Duiker, S.W.; Rhoton, F.E.; Torrent, J.; Smeck, N.E.; Lal, R. Iron (Hydr)Oxide Crystallinity Effects on Soil Aggregation. Soil Sci. Soc. Am. J. 2003, 67, 606-611. [CrossRef] 
14. Oades, J.M. Soil organic matter and structural stability: Mechanisms and implications for management. Plant Soil 1984, 76, 319-337. [CrossRef]

15. Keiluweit, M.; Bougoure, J.J.; Nico, P.S.; Pett-Ridge, J.; Weber, P.K.; Kleber, M. Mineral protection of soil carbon counteracted by root exudates. Nat. Clim. Chang. 2015, 5, 588-595. [CrossRef]

16. Six, J.; Paustian, K.; Elliott, E.T.; Combrink, C. Soil Structure and Organic Matter I. Distribution of Aggregate-Size Classes and Aggregate-Associated Carbon. Soil Sci. Soc. Am. J. 2000, 64, 681-689. [CrossRef]

17. Sollins, P.; Swanston, C.; Kleber, M.; Filley, T.; Kramer, M.; Crow, S.; Caldwell, B.A.; Lajtha, K.; Bowden, R. Organic $C$ and $N$ stabilization in a forest soil: Evidence from sequential density fractionation. Soil Biol. Biochem. 2006, 38, 3313-3324. [CrossRef]

18. Moni, C.; Derrien, D.; Hatton, P.J.; Zeller, B.; Kleber, M. Density fractions versus size separates: Does physical fractionation isolate functional soil compartments? Biogeosciences 2012, 9, 5181-5197. [CrossRef]

19. Hatton, P.-J.; Kleber, M.; Zeller, B.; Moni, C.; Plante, A.F.; Townsend, K.; Gelhaye, L.; Lajtha, K.; Derrien, D. Transfer of litter-derived $\mathrm{N}$ to soil mineral-organic associations: Evidence from decadal $15 \mathrm{~N}$ tracer experiments. Org. Geochem. 2012, 42, 1489-1501. [CrossRef]

20. Golchin, A.; Oades, J.; Skjemstad, J.; Clarke, P. Study of free and occluded particulate organic matter in soils by solid state 13C Cp/MAS NMR spectroscopy and scanning electron microscopy. Soil Res. 1994, 32, $285-309$. [CrossRef]

21. Golchin, A.; Oades, J.M.; Skjemstad, J.O.; Clarke, P.; Golchin, A.; Oades, J.M.; Skjemstad, J.O.; Clarke, P. Soil structure and carbon cycling, Soil structure and carbon cycling. Soil Res. Soil Res. 1994, 32, 1043-1068. [CrossRef]

22. Regier, T.; Krochak, J.; Sham, T.K.; Hu, Y.F.; Thompson, J.; Blyth, R.I.R. Performance and capabilities of the Canadian Dragon: The SGM beamline at the Canadian Light Source. Nucl. Instrum. Methods Phys. Res. Sect. A Accel. Spectrometers Detect. Assoc. Equip. 2007, 582, 93-95. [CrossRef]

23. Gillespie, A.W.; Phillips, C.L.; Dynes, J.J.; Chevrier, D.; Regier, T.Z.; Peak, D. Chapter One-Advances in Using Soft X-Ray Spectroscopy for Measurement of Soil Biogeochemical Processes. In Advances in Agronomy; Sparks, D.L., Ed.; Academic Press: Cambridge, MA, USA, 2015; Volume 133, pp. 1-32.

24. Ravel, B.; Newville, M. Athena, Artemis, Hephaestus: Data analysis for X-ray absorption spectroscopy using IFEFFIT. J. Synchrotron Radiat. 2005, 12, 537-541. [CrossRef] [PubMed]

25. McKeague, J.A.; Day, J.H. Dithionite and oxalate extractable $\mathrm{Fe}$ and $\mathrm{Al}$ as in differentiating various classes of soils. Can. J. Soil. Sci. 1966, 46, 13-22. [CrossRef]

26. Degens, B.P. Macro-aggregation of soils by biological bonding and binding mechanisms and the factors affecting these: A review. Soil Res. 1997, 35, 431-460. [CrossRef]

27. Angers, D.A.; Caron, J. Plant-induced Changes in Soil Structure: Processes and Feedbacks. Biogeochemistry 1998, 42, 55-72. [CrossRef]

28. Six, J.; Bossuyt, H.; Degryze, S.; Denef, K. A history of research on the link between (micro)aggregates, soil biota, and soil organic matter dynamics. Soil Tillage Res. 2004, 79, 7-31. [CrossRef]

29. Helal, H.M.; Sauerbeck, D.R. Influence of plant roots on C and P metabolism in soil, Developments in Plant and Soil Sciences. In Biological Processes and Soil Fertility; Tinsley, J., Darbyshire, J.F., Eds.; Springer: Dordrecht, The Netherlands, 1984; pp. 175-182.

30. Gale, W.J.; Cambardella, C.A.; Bailey, T.B. Root-Derived Carbon and the Formation and Stabilization of Aggregates. Soil Sci. Soc. Am. J. 2000, 64, 201-207. [CrossRef]

31. Daynes, C.N.; Field, D.J.; Saleeba, J.A.; Cole, M.A.; McGee, P.A. Development and stabilisation of soil structure via interactions between organic matter, arbuscular mycorrhizal fungi and plant roots. Soil Biol. Biochem. 2013, 57, 683-694. [CrossRef]

32. Denef, K.; Six, J.; Bossuyt, H.; Frey, S.D.; Elliott, E.T.; Merckx, R.; Paustian, K. Influence of dry-wet cycles on the interrelationship between aggregate, particulate organic matter, and microbial community dynamics. Soil Biol. Biochem. 2001, 33, 1599-1611. [CrossRef]

33. Denef, K.; Six, J. Clay mineralogy determines the importance of biological versus abiotic processes for macroaggregate formation and stabilization. Eur. J. Soil Sci. 2005, 56, 469-479. [CrossRef]

34. Banfield, J.F.; Barker, W.W.; Welch, S.A.; Taunton, A. Biological impact on mineral dissolution: Application of the lichen model to understanding mineral weathering in the rhizosphere. Proc. Natl. Acad. Sci. USA 1999, 96, 3404-3411. [CrossRef] [PubMed] 
35. Easterwood, G.W.; Sartain, J.B. Clover Residue Effectiveness in Reducing Orthophosphate Sorption on Ferric Hydroxide Coated Soil. Soil Sci. Soc. Am. J. 1990, 54, 1345-1350. [CrossRef]

36. Gerke, J. Phosphate adsorption by humic/Fe-oxide mixtures aged at $\mathrm{pH} 4$ and 7 and by poorly ordered Fe-oxide. Geoderma 1993, 59, 279-288. [CrossRef]

37. Miller, R.M.; Jastrow, J.D. Mycorrhizal Fungi Influence Soil Structure. In Arbuscular Mycorrhizas: Physiology and Function; Kapulnik, Y., Douds, D.D., Eds.; Springer: Dordrecht, The Netherlands, 2000; pp. 3-18.

38. Schwertmann, U. Solubility and dissolution of iron oxides. Plant Soil 1991, 130, 1-25. [CrossRef]

39. Schwertmann, U.; Friedl, J.; Stanjek, H. From Fe(III) Ions to Ferrihydrite and then to Hematite. J. Colloid Interface Sci. 1999, 209, 215-223. [CrossRef]

40. Hansel, C.M.; Benner, S.G.; Fendorf, S. Competing Fe(II)-induced mineralization pathways of ferrihydrite. Environ. Sci. Technol. 2005, 39, 7147-7153. [CrossRef]

(C) 2020 by the authors. Licensee MDPI, Basel, Switzerland. This article is an open access article distributed under the terms and conditions of the Creative Commons Attribution (CC BY) license (http://creativecommons.org/licenses/by/4.0/). 